\title{
Syringe micro vibrator (SMV) a new device being introduced in dentistry to alleviate pain and anxiety of intraoral injections, and a comparative study with a similar device
}

Amir Hashem Shahidi Bonjar

\begin{abstract}
Background: Neurologically, it is proven that stimulation of larger diameter fibers - e.g. using appropriate coldness, warmth, rubbing, pressure or vibration- can close the neural "gate" so that the central perception of itch and pain is reduced. This fact is based upon "Gate-control" theory of Melzack and Wall.

Presentation of the hypothesis: Syringe Micro Vibrator is a new design being introduced for the first time in the field of Dentistry. This device is a promising breakthrough in pain and anxiety management and may deliver solution for clinicians plagued with patient pain phobia. It has an off-set rotating micro vibration creator with ultra high frequency and ultra low altitude that can be easily placed on any standard dental syringe and some disposable syringes. This device was registered as an invention in dentistry and received Iran National Patent number of 63765.

Testing the hypothesis: By creating micro vibration, this device would be effective in reducing the pain and anxiety confronted with most types of intraoral injections as palatal, mandibular block, intraligamental and local infiltration. From the aspect of the patient pain management, this device contributes both physiologically (based on Gate Control Theory of pain) and psychologically (based on the device function as will be explained by dentist to the patient as a modern pain reducing technology). From the aspect of clinician, SMV motor provides vibrations with ultra high frequency to alleviate pain, but since it has ultra low vibration altitude, it has no adverse effect on the clinician dexterity and accuracy during injection and it does not interfere with pin point localization of injection site.

Implications of the hypothesis: Upon mounting on a conventional dental anesthesia injection syringe, SMV is switched on and the clinician then uses normal injection technique to administer the anesthetic. This device is not only a useful accessory device for ordinary patients, but also more useful for pediatric patients and those who have a phobia of intraoral injection or pain.
\end{abstract}

\section{Background}

Pain is an unpleasant sensory and emotional experience associated with actual or potential tissue damage, or described in terms of such damage [1]. Pain management, also called algiatry, employs an interdisciplinary approach for easing the suffering and improving the quality of life of those experiencing pain [2]. Because of

Correspondence: shahidiah@gmail.com

Student of Dentistry, Students Research Committee, School of Dentistry, Shahid Beheshti Medical University, Evin, Tehran 1983963113, Iran the fear of pain in dental injections, some people avoid, cancel or do not appear for dental appointments [3]. Pain and anxiety control is one of the most important aspects in administration of local anesthetic in dental practice. Administration of local anesthetic produces pain and anxiety that may cause subsequent unfavorable behavior [4]. The levels of, and relationships between dental fear, general fears and phobias were studied by Berggren in 109 adult patients at a specialized dental fear clinic using two dental fear scales [5]. The results 
indicated that a large proportion of these dentally fearful individuals were prone to injection fear. The pain induced by infiltration of local anesthetic agents can be reduced in a number of complementary methods which include application of topical analgesics such as methocaine [6], suggestion [7], distraction techniques [8], counter irritation $[9,10]$, varying the rates of infiltration [11], buffering the local anesthesia [12-15], reduced speed of injection [16,17] and use of vibration [18-23]. Melzack and Schecter [24] showed that itch can be reduced by vibration of stimulated area. They concluded that their results may be attributed to physiological activities occurring at the early stages of information transmission. Vibratory stimulation is a potential method for the treatment of pain. It is one of several non-pharmacological techniques used to reduce pain [25]. The effects of vibration on pain have been reported in both clinical $[21,26]$ and experimental settings $[18,27]$. Vibration activates both superficial and deeply located receptors $[18,22,28]$. Lundeberg et al proved reduction of pain during vibratory stimulation in patients suffering acute or chronic musculoskeletal pain of different origin. They noticed that sixty-nine per cent of the patients reported a reduction of pain during vibratory stimulation $[19,20,27]$. Nanitsos et al investigated the effect of vibration on pain during local anesthesia injections. Their results indicated that compared to no vibration-stimulus injections, injections with vibration resulted in less pain and lower pain rating by studied patients [19]. Based on gate control theory $[29,30]$, mechanisms of pain relief induced by vibration are elaborated by several workers suggesting pain can be reduced by simultaneous activation of nerve fibers that conduct non-noxious stimuli $[1,19,20]$. In this regard Longe et al [31] and Aminabadi [9] indicated that counter stimulation reduces pain perception. They concluded that when vibration is applied as a counter stimulation to an anesthetic injection, it will reach the brain before the pain sensation does. The brain can perceive only one sensation at a time; therefore, the sensation that arrives at the brain first is the one that will be felt. Syringe Micro Vibrator is a new design being introduced for the first time in the field of Dentistry. As a vibration stimulus, structural constituents, analogy and the role of SMV to alleviate patient pain and anxiety during dental anesthesia injection would be discussed hereafter.

\section{Presentation of the hypothesis}

SMV was designed to provide feasibility to alleviate injection pain and anxiety in clinical practice. Upon mounting on a conventional dental anesthesia injection syringe, its motor is switched on and the clinician then uses normal injection technique to administer the anesthetic. Its parallel mounting on the syringe allows clinician to rotate the syringe while in the mouth, if necessary. Its main structural parts consist of a) stainless steel shell bearing four flexible attachment arms, b) eccentrically weighted plate and motor, and c) two button batteries. SMV is registered as an invention in the field of dentistry and received Iran National Patent number of 63765. Schematic mounting position of SMV on injection syringe is indicated in Figure 1.

\section{Testing the hypothesis}

Micro vibration of injection needle with ultra high frequency and ultra low altitude will alleviate the pain and anxiety during intraoral injections. SMV bears an off-set rotating micro vibration motor and can be easily mounted on any standard dental syringe. Accordingly, "Pain gate" would be shut by stimulating nerves providing reduction in patient pain and discomfort during injection period. SMV makes nerve endings sense micro vibrations at the very early stage, so will remarkably reduce the pain transmission. Implication of SMV would have advantages of: 1) From the aspect of the patient pain management, SMV contributes both physiologically (based on Gate Control Theory of pain) and psychologically (based on the device function as will be explained by dentist to the patient as a modern pain reducing technology), 2) from the aspect of clinician, SMV motor provides vibrations with ultra high frequency to alleviate pain, but since it has ultra low vibration altitude, it has no adverse effect on the clinician dexterity and accuracy during injection and it does not interfere with pin point localization of injection site, 3) it alleviates two types of pain injection including both needle insertion pain and balloon effect due to forceful penetration of anesthetic into the surrounding tissue. The micro vibration slowly reduces such balloon and enhances tissue infiltration of injected anesthesia, 4) it is easy to use and does not provide any inconvenience for the clinician during injection operation due to a- low weight that does not affect the accuracy of clinician, bsmall size that keeps well visibility, c- battery powered and lack of wire or hose attachment, 5) firm grasp by four flexible attachment arms it provides: a- convey of efficient vibration to syringe barrel and consequently to needle, b-applicable to all standard conventional syringes and compensates minute variations of different barrel diameters, c- no screw or spare appliance needed for its mounting to or removal from the syringe barrel, so its application is fast and easy, $d$ - it can be attached anywhere along the syringe barrel while it does not cover or mask the cartridge, 6) no need to replace the existing syringes or purchase further spare parts, 7) it has a detachable motor, a stainless steel shell and four attachment arms which are autoclavable and are the only parts in contact with patient during injection. 


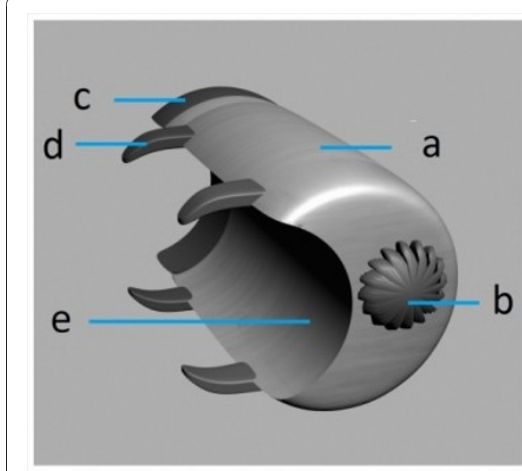

A

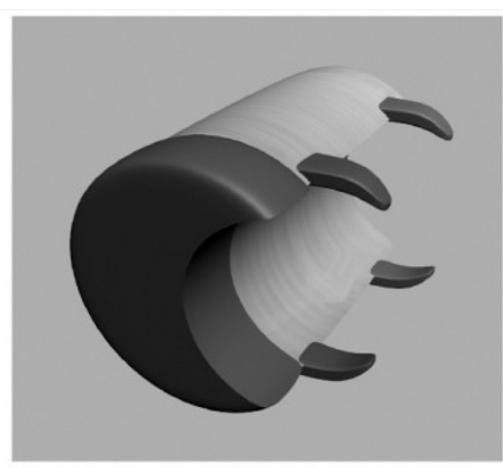

B

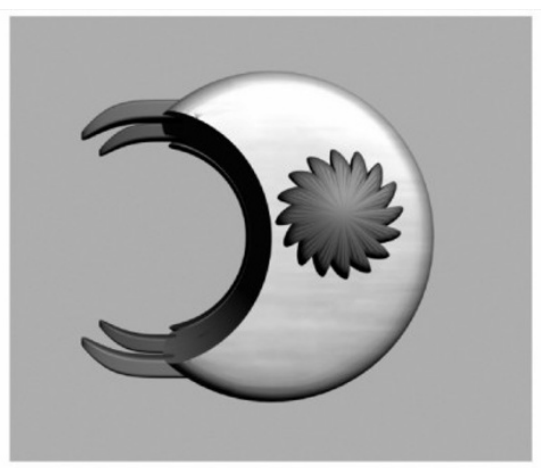

C
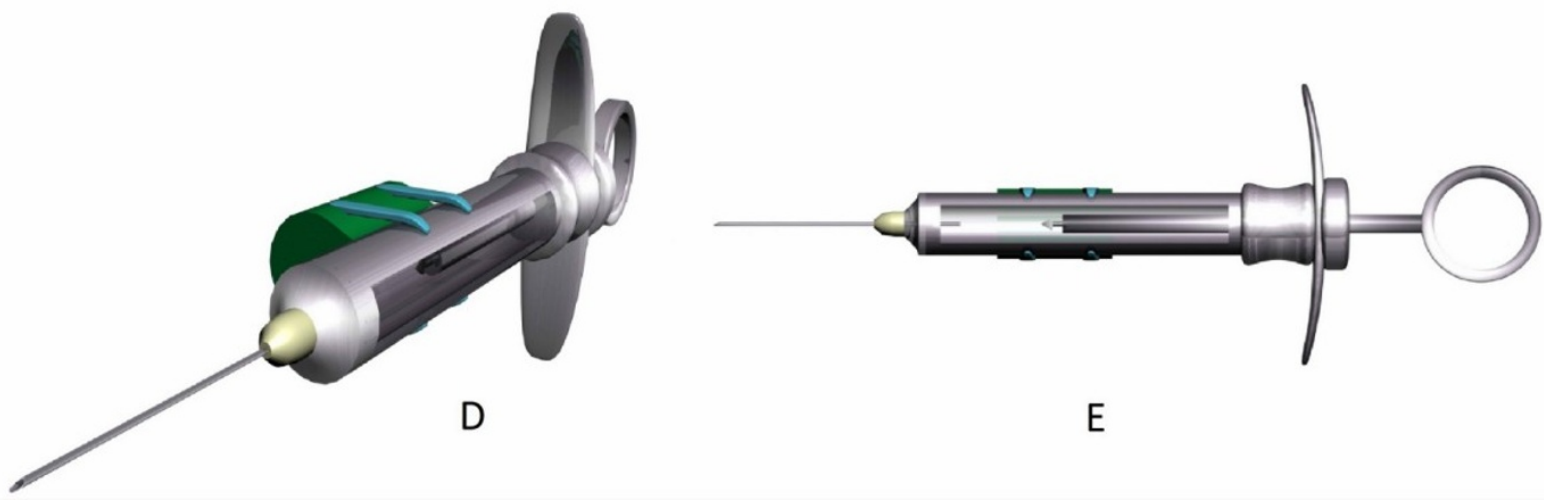

$E$

Figure 1 Structural components of Syringe Micro Vibrator (SMV) and its mounting position on dental syringe barrel. A) Posterioranterior view of SMV, structural components consist of: a) stainless steel shell containing motor and eccentrically weighted plate, b) power switch, c) stainless steel cap, d) four flexible attachment arms for firm attachment and e) shell concavity for well adaptation on syringe barrel. B) Anterior-posterior view of SMV and stainless steel cap bearing button cell batteries, C) SMV is applicable to most standard conventional syringes which compensates minute variations of different barrel diameters through four flexible grasping positioning arms and shell concavity, D) SMV mounted on syringe barrel and E) Lateral syringe view indicates that mounting of SMV causes no restriction for the replacement of cartridge.

The motor should not be heat sterilized but for disinfestations, it can be easily removed from its shell socket before autoclaving or can be wiped off with a surface disinfestant and 8) use of SMV would save time since it eliminates the period needed for application and onset of topical anesthetic. It also shortens period of anesthesia onset with increase of anesthetic diffusion pace to surrounding tissues since the ultra vibration enhances tissue infiltration of injected anesthetic.

\section{Simplicity of application}

Implication of SMV requires no topical anesthetic or special technique. SMV would weigh approximately 3050 grams and would be easily mounted on dental injection syringes. The SMV package would bear motor assembly, autoclavable stainless steel shell bearing flexible attachment arms, two button batteries, a recharging unit and power cord. SMV will bring more comfort for both patient and the physician during the process of injection. This device by creating micro vibration would be effective in reducing the pain and anxiety confronted with most types of intraoral injections as palatal, mandibular block, intraligamental and local infiltration.

\section{Discussion}

Most patients feel physically and psychologically uncomfortable about penetration of injecting needle into their oral tissues. Some of them do not convey this feeling to the clinician, so the number of patients fearful of the dental pain experience and feeling discomfort is more than what is seen in clinic, however, in many patients fear of injection contributes significantly to postponement of dental treatment however, less painful injection experience with SMV lowers the future fear of injection in such patients. The "Gate-control" theory $[29,30]$ reveals that using appropriate pressure or vibration can close the neural "gate" so that the central perception of itch and pain is reduced. In other words, the "Pain gate" 
Table 1 Comparative study indicating specification differences between Syringe Micro Vibrator (SMV) and VibraJect ${ }^{\circledR}$

\begin{tabular}{|c|c|c|c|}
\hline Specifications & VibraJect $^{\circledR}$ & SMV & Advantage of SMV \\
\hline $\begin{array}{l}\text { Attachment } \\
\text { interface }\end{array}$ & Clip & $\begin{array}{l}\text { Four flexible grasping positioning } \\
\text { arms and concave shell contact } \\
\text { surface }\end{array}$ & $\begin{array}{l}\text { Firm grasping, efficient vibration conveyance, causes no restriction for the } \\
\text { replacement of cartridge, applicable to all standard conventional syringes } \\
\text { which compensates minute variations of different barrel diameters }\end{array}$ \\
\hline $\begin{array}{l}\text { Mounting angle } \\
\text { on syringe barrel }\end{array}$ & Angular & Parallel & $\begin{array}{l}\text { Most efficient contact, least clinician vision masking, least patient } \\
\text { discomfort, allowing the clinician to rotate the syringe while in the mouth, } \\
\text { if necessary }\end{array}$ \\
\hline Vibration device & $\begin{array}{l}\text { Eccentrically } \\
\text { weighted } \\
\text { shaft }\end{array}$ & Eccentrically weighted plate & $\begin{array}{l}\text { Yield of uniform micro vibration, more precise localization of injection } \\
\text { point }\end{array}$ \\
\hline Vibration mode & $\begin{array}{l}\text { High } \\
\text { frequency }\end{array}$ & $\begin{array}{l}\text { Ultra high frequency and ultra low } \\
\text { altitude }\end{array}$ & $\begin{array}{l}\text { Efficiently enhance patient pain reduction, and ease of clinician maneuver } \\
\text { and accuracy during injection }\end{array}$ \\
\hline
\end{tabular}

can be shut by stimulating nerves responsible for carrying the signals which enable the relief of pain through massage techniques, rubbing, pressure, ice packs, acupuncture, electrical analgesia and the application of vibration. Examples of less pain experiences based on Gate theory may be seen in: a- Incision in bare hands while playing in snow feels less pain than normal, b- use of simultaneous cold and vibration in ladies epilating devices as accessory stimuli reduces transmission of main stimulus by local nerve endings in hair removal leading to reduced prick and c-some dentists have developed pain reducing techniques like shaking the syringe in their grasp while dispensing the anesthetic [25].

\section{Comparative study}

A similar device reported in the literature, Vibraject ${ }^{\mathbb{R}}$, has controversial performance. Blair [32] recommended the use of VibraJect ${ }^{\circledR}$ for painless injection. In contrast, Yoshikawa et al [33] found no significant pain reduction when VibraJect ${ }^{\mathbb{B}}$ was applied with a conventional dental syringe. Saijo et al [34] evaluated the effectiveness of VibraJect ${ }^{\circledR}$ in combination with an electrical injection device. Injections were given into the alveolar mucosa adjacent to the root apex of the maxillary lateral incisor in 10 volunteers. VibraJect ${ }^{\circledR}$ was randomly applied to either the left or right side of the injection. They found no statistically supports use of VibraJect ${ }^{\circledR}$ but expressed that it offers a simple and easy-to-use solution that can anesthetize patients quickly in a more comfortable manner. They also point out that VibraJect ${ }^{\circledR}$ enables a less painful palatal injection because it delivers small amounts of anesthetic solution over a period of time. Another supporting result was statistically performed by Purray et al [35] at Queens University with conclusion that the vibrating syringe attachment resulted in reduced pain levels on receiving intraoral injections. The study performed on 400 patients and showed that Vibraject ${ }^{\circledR}$ statistically reduced the amount of pain score from 4.6 to 1.7 which has never been statistically achieved before. Accordingly it is conclusive that VibraJect ${ }^{\circledR}$ effectiveness is approved, however as indicated in Table 1 SMV has improvements in several structural features including vibration mode bringing enhanced effectiveness to the method of using vibration in dental anesthesia injection. In the table, technical features, performance and a brief summary for specification differences between SMV and VibraJect ${ }^{\circledR}$ are indicated correspondingly. At last, it should be pointed out that SMV is not only a useful accessory device for ordinary patients, but also more useful for pediatric patients and those who have a phobia of intraoral injection or pain. The author believes SMV will bring more comfort for both patient and the physician during the process of injection.

Accordingly, what expressed in this article about using SMV is based upon potential usefulness of vibratory stimulation for pain since vibration would increase the threshold for dental injection pain as indicated in earlier findings of other researchers $[18,23,36]$. The author expresses that although SMV is designed to alleviate the injection pain during anesthesia injections, there may be no significant difference in pain perception in patients with a higher pain tolerance. Since pain tolerance cannot be estimated ahead of injection [37], it is recommended to use SMV for most patients.

\section{Implications of the hypothesis}

SMV is a useful accessory device adaptable for dental injection syringe and conventional intra muscular injections to alleviate pain and stress of injection.

\section{Abbreviations \\ SMV: Syringe Micro Vibrator.}

\section{Acknowledgements}

I like to express my deepest thanks for help, scientific advice and support to: Professor M. Yaghmaei, Oral and Maxillofacial Surgeon and Head of the Oral and Maxillofacial Surgery Department; Dr A. Khojasteh, Oral and Maxillofacial Surgeon and Head of Exceptional Talent Center of the College of Dentistry; Dr M. Nouri, Orthodontist and Head of Communication and Information Technology Center; Dr F. Poordanesh, Oral and Maxillofacial Surgeon; Dr O. Diyanat, Endodontist; Dental School, Shahid Beheshti University of Medical Sciences, Tehran, Iran. 


\section{Authors' contributions}

AHSB carried out the entire design of the study and draft the manuscript. He read and approved the final manuscript.

\section{Competing interests}

The authors declares that he has no competing interests.

Received: 20 March 2010 Accepted: 7 January 2011

Published: 7 January 2011

\section{References}

1. IASP Task Force on Taxonomy: Part III: Pain Terms, a Current List with Definitions and Notes on Usage. In Classification of Chronic Pain.. 2 edition. Edited by: Merskey H, Bogduk N. WA, Seattle; IASP Press; 1994:209-214.

2. Hardy PAJ: Chronic pain management: the essentials. UK; Greenwich Medical Media; 1997, 13-21.

3. Milgrom P, Codwell SE, Getz T, Weinstein P, Ramsay DS: Four dimentions of fear of dental injections. J Am Dent Assoc 1997, 128:756-66.

4. Fiset L, Milgrom P, Weinstein P, Getz T, Glassman P: Psycophysiological responses to dental injections. J Am Dent Assoc 1985, 111:578-583.

5. Berggren U: General and specific fears in referred and self-referred adult patients with extreme dental anxiety. Behav Res Ther 1992, 40:395-401.

6. O'Brien L, Taddio A, Lyszkiewicz DA, Koren G: A critical review of the topical local anesthetic amethocaine (Ametop) for pediatric pain. Paediatr Drugs 2005, 7:41-54.

7. Pollack S: Pain control by suggestion. J Oral Med 1966, 21:89-95.

8. Touyz LZ, Lamontagne P, Smith BE: Pain and anxiety reduction using a manual stimulation distraction device when administering local analgesia oro-dental injections: a multi-center clinical investigation. J Clin Dent 2004, 15:88-92.

9. Aminabadi NA, Farahani RM, Balayi Gajan E: The efficacy of distraction and counter stimulation in the reduction of pain reaction in intraoral injection by pediatric patients. The J Contemp Dent Pract 2009, 9:33-40.

10. Ong EL, Lim NL, Koay CK: Towards a pain free venopuncture. Anaesthesid 2000, 55:260-262.

11. Scarfone RJ, Jasani M, Gracely EJ: Pain of local anesthetics: rate of administration and buffering. Ann Emerg Med 1998, 31:36-40.

12. Colaric KB, Overton DT, Moore K: Pain reduction in lidocaine administration through buffering and warming. Am J Emerg Med 1998, 16:353-365.

13. Masters JE: Randomized control trial of $\mathrm{pH}$ buffered lignocaine with adrenaline in outpatient operations. Br J Plast Surg 1998, 51:385-387.

14. Orlinsky M, Hudson C, Chan L, Deslauriers R: Pain comparison of unbuffered versus buffered lidocaine in local wound infiltration. $J$ Emerg Med 1992, 10:411-415.

15. Younis I, Bhutiani RP: Taking the 'ouch' out- effect of buffering commertial xylocaine on infiltration and procedure pain - a positive, randomized, doubleblind, controlled trial. Ann R Coll Surg Engl 2004, 86:213-7.

16. Bartfield JM, Crisaffulia KM, Raccio-Robak N, Salluzzo RF: The effects of warming and buffering on pain of infiltration of lidocaine. Acad Emerg Med 1995, 2:254-8

17. Fitton AR, Ragbir M, Milling MA: The use of $\mathrm{pH}$ adjusted lingnocaine in controlling operative pain in the day surgery unit: a positive randomized trial. Br J Plast Surg 1996, 49:404-8.

18. Kakigi R, Shibasaki H: Mechanisms of pain relief by vibration and movement. J Neurol Neurosurg Psychiatry 1992, 55:282-286.

19. Lundeberg T, Nordemar R, Ottoson D: Pain alleviation by vibration stimulation. Pain 1984, 20: 25-44.

20. Nanitsos E, Vartuli R, Forte A, Dennison PJ, Peck CC: The effect of vibration on pain during local anaesthesia injections. Aust Dent J 2010, 54:94-100.

21. Roy EA, Hollins M, Maixner W: Reduction of TMD pain by high-frequency vibration: a spatial and temporal analysis. Pain 2003, 101:267-74.

22. Weerakkoby NS, Percival P, Hickey MW, Morgan DL, Gregory JE, Canny BJ, Porske U: Effects of local pressure and vibration on muscle pain from eccentric exercise and hypertonic saline. Pain 2003, 105:425-435.

23. Yarnitsky D, Kunin M, Brik R, Specher E: Vibration reduces thermal pain adjacent dermatomes. Pain 1997, 69:75-7.

24. Melzack R, Schecter B: Itch and vibration. Science 1965, 26:1047-8

25. Dahlin L, Lund I, Lundberg T, Molander C: Vibratory stimulation increases the electro-cutaneous sensory detection and pain thresholds in women but not in men. BMC Complement Altern Med 2006, 6:20.
26. Ottoson D, Ekblom A, Hasson P: Vibratory stimulation for the relief of pain of dental origin. Pain 1981, 10:37-45

27. Lundeberg T, Abrahamsson P, Bondesson L, Haker E: Effect of vibratory stimulation on experimental and clinical pain. Scand J Rehabil Med 1988 20:149-169.

28. Hagbarth KE, Eklund G: Motor effects of muscle vibration in spasticity, rigidity and cerebellar disorders. J Neurol Neurosurg Psychiatry 1968, 31:207-213.

29. Melzack R, Wall P: Pain mechanisms: a new theory. Science 1965 150:971-979

30. Sufka K, Price DD: Gate Control Theory reconsidered. Brain Mind 2002, 2:277-90.

31. Wright GZ: Nonpharmacologic management of children's behaviors. In Dentistry for the child and adolescent.. 8 edition. Edited by: McDonald RE, Avery DR, Dean JA. St Louis: Mosby; 1994:38-39.

32. Zoppi M, Voegelin MR, Signorini M, Zamponi A: Pain threshold changes by skin vibratory stimulation in healthy subjects. Acta Physiol Scand 1991, 143:439-443.

33. Blair J: Vibraject from ITL Dental. Dent Econ 2002, 92:90

34. Yoshikawa F, Ushito D, Ohe D, Shirasishi Y, Fukayama H, Umino M: Vibrating dental local anesthesia attachment to reduce injection pain. $J$ Jpn Dent Soc Anesthesiol 2003, 31:194-195.

35. Saijo M, Ito E, Ichinohe T, Kaneko Y: Lack of Pain Reduction by a Vibrating Local Anesthetic Attachment: A Pilot Study. Anesthesiol Prog 2005, 52:62-64.

36. DentistrylQ: Minimizing injection pain and stress.[http://www.dentistryiq com/index/display/article-display/2733297848/articles/dentisryiq/clinical/ 2010/02/Minimizing-injection-pain-and-stress.html].

37. Litt MD: A model of pain and anxiety associated with acute stressors: Distress in dental procedures. Behav Res Ther 1996, 34:459-76.

doi:10.1186/1750-1164-5-1

Cite this article as: Shahidi Bonjar: Syringe micro vibrator (SMV) a new device being introduced in dentistry to alleviate pain and anxiety of intraoral injections, and a comparative study with a similar device. Annals of Surgical Innovation and Research 2011 5:1.

\section{Submit your next manuscript to BioMed Central and take full advantage of:}

- Convenient online submission

- Thorough peer review

- No space constraints or color figure charges

- Immediate publication on acceptance

- Inclusion in PubMed, CAS, Scopus and Google Scholar

- Research which is freely available for redistribution

Submit your manuscript at www.biomedcentral.com/submit
Ciomed Central 